\title{
Phenotypic selection on floral scent: trade-off between attraction and deterrence?
}

\author{
Schiestl, F P ; Huber, F K ; Gomez, J M
}

\begin{abstract}
Flowers emit a large variety of floral signals that play a fundamental role in the communication of plants with their mutualists and antagonists. We investigated phenotypic selection on floral scent and floral display using the rewarding orchid species Gymnadenia odoratissima. We found positive directional selection on inflorescence size, as well as positive and negative selection on floral scent compounds. Structural equation modeling showed that "active" compounds, i.e. those that were shown in earlier investigations to be detected by pollinator insects, were positively linked to fitness, whereas "non-active" were negatively linked to fitness. Our results suggest that different patterns of selection impact on different scent compounds, which may relate to the functions of compounds for attracting/deterring insects.
\end{abstract}

DOI: https://doi.org/10.1007/s10682-010-9409-y

Posted at the Zurich Open Repository and Archive, University of Zurich

ZORA URL: https://doi.org/10.5167/uzh-35778

Journal Article

Published Version

Originally published at:

Schiestl, F P; Huber, F K; Gomez, J M (2011). Phenotypic selection on floral scent: trade-off between attraction and deterrence? Evolutionary Ecology, 25(2):237-248.

DOI: https://doi.org/10.1007/s10682-010-9409-y 


\title{
Phenotypic selection on floral scent: trade-off between attraction and deterrence?
}

\author{
Florian P. Schiestl • Franz K. Huber • José M. Gomez
}

Received: 6 August 2009/Accepted: 10 July 2010/Published online: 20 July 2010

(C) Springer Science+Business Media B.V. 2010

\begin{abstract}
Flowers emit a large variety of floral signals that play a fundamental role in the communication of plants with their mutualists and antagonists. We investigated phenotypic selection on floral scent and floral display using the rewarding orchid species Gymnadenia odoratissima. We found positive directional selection on inflorescence size, as well as positive and negative selection on floral scent compounds. Structural equation modeling showed that "active" compounds, i.e. those that were shown in earlier investigations to be detected by pollinator insects, were positively linked to fitness, whereas "non-active" were negatively linked to fitness. Our results suggest that different patterns of selection impact on different scent compounds, which may relate to the functions of compounds for attracting/deterring insects.
\end{abstract}

Keywords Pollination $\cdot$ Floral evolution $\cdot$ VOC $\cdot$ Plant volatiles $\cdot$ Herbivory

\section{Introduction}

The angiosperms have evolved an enormous diversity of flowers, comprising vast variation in shape, color, and scent. Although there is common agreement that pollinators play an important role in floral evolution, the details of this process are still little understood (Johnson 2006). Pollinators mediate reproductive success and reproductive isolation among plants, and can select for floral signals through innate sensory preferences (Melendez-Ackerman et al. 1997; Vereecken and Schiestl 2008), learning (Chittka et al. 1999; Goyret et al. 2008) and morphology (Benitez-Vieyra et al. 2006; Gomez et al. 2008). Since these traits differ among pollinators, adaptation to different pollinators can drive floral diversification through selection. Studies on a number of plant species have shown that floral traits may be under pollinator-mediated selection, but not all traits have attracted

F. P. Schiestl $(\bowtie) \cdot$ F. K. Huber

Institute of Systematic Botany, University of Zürich, Zollikerstrasse 107, 8008 Zurich, Switzerland e-mail: florian.schiestl@systbot.uzh.ch

J. M. Gomez

Dpto Ecología, Universidad de Granada, Avda Fuentenueva s/n, 18071 Granada, Spain 
a similar degree of attention. Much of our understanding of pollinator-mediated selection derives from studies on flower and inflorescence size (Benitez-Vieyra et al. 2006; Maad 2000; Maad and Alexandersson 2004; O'Connell and Johnston 1998), floral color (Aragon and Ackerman 2004; Gomez 2000; Melendez-Ackerman and Campbell 1998; MelendezAckerman et al. 1997; Streisfeld and Kohn 2007) and flower shape (Benitez-Vieyra et al. 2006; Gomez et al. 2008; Herrera et al. 2006). Floral scent, however, has been given less attention in the context of selection studies, probably due to its comparably demanding sampling and analysis (Ayasse et al. 2000; Galen et al. 1987; Mant et al. 2005; Pellmyr 1986; Salzmann et al. 2007b). As a consequence, our understanding of the evolution of floral scent is still in its infancy, despite the general recognition of this trait as one of the key signals for plant-animal interactions (Raguso 2008; Schiestl 2010). Much of the past work on floral scent has focused on the identification of scent compounds (volatile organic compounds, VOCs), leading to the identification of an intriguing chemical diversity produced by flowers (Knudsen et al. 2006). Functional studies have shown that floral scent mediates a number of different interactions, as it attracts/repels (specific) pollinators, granivores, and herbivores (Baldwin et al. 1997; Dötterl et al. 2006; Huber et al. 2005; Kessler et al. 2008; Ômura et al. 2000; Plepys et al. 2002) and is thus an important factor for outcrossing (Kessler et al. 2008), species isolation (Waelti et al. 2008), and damage to seeds and vegetative parts of the plant (Baldwin et al. 1997). Floral scent compounds can also act as a powerful anti-microbial agent (Steinebrunner et al. 2008). Despite this wealth of functions and the clear importance of scent in the ecology of plants, studies on phenotypic selection on individual floral scent compounds have not yet been done.

Whereas functions of individual scent compounds have been highlighted in a number of cases, much less is known about proximate and ultimate reasons for the evolution of complex scent bouquets. Only as a rare exception, flowers emit single compounds (Schiestl et al. 2003; Wiemer et al. 2009), but usually fragrance consists of complex blends of VOCs originating from different biosynthetic pathways (Raguso 2008). Such bouquets are often taxon- or population specific, by means of different qualitative composition, or just different proportions of the same compounds (Chess et al. 2008; Huber et al. 2005; Mant et al. 2005; Salzmann et al. 2007a). Different compounds in a bouquet can have different functions, thus the production of a range of different compounds can help the plant to fulfill different tasks in its interaction with other organisms. In the communication with pollinators, however, bouquets are also thought to have important signaling functions in the learning and discrimination of flowers by insects (Raguso 2008). We used the rewarding orchid species Gymnadenia odoratissima to investigate the connection between fruit production, inflorescence size, and floral scent emission, by combining multivariate regression and structural equation modeling to assess patterns of selection on floral scent bouquets.

\section{Materials and methods}

The study system

Gymnadenia odoratissima (L.) L.C.M. Richard is a widely distributed orchid in Central Europe, pollinated mostly by butterfly and moths species (Huber et al. 2005; Schiestl and Schlüter 2009). In the study populations G. odoratissima is pollinated by Tortricidae, Pterophoridae, Pyralidae, Lycaenidae, and Geometridae (Huber et al. 2005). Plants flower from mid June to beginning of August, and produce inflorescences with 9-47 flowers (mean $\pm \mathrm{SD}=26.77 \pm 9.14$; own unpublished data). Fruit set varies from 0 to $93 \%$ 
(mean $=46.5 \pm 20.01 \%$ ), suggesting pollination limitation in reproductive success (Huber et al. 2005). However, pollination limitation was not yet confirmed by pollination experiments. The flowers emit a strong floral scent, consisting of a blend of more than 40 compounds. In earlier investigations, gas chromatography coupled to electrophysiological detection (GC-EAD) was used to identify "active" compounds, i.e. such that elicit significant responses in the olfactory neurons of the pollinators' antennae (Huber et al. 2005). Seven such active compounds were found in G. odoratissima. Successively, a blend of active compounds, as well as phenylacetaldehyde alone, was found to attract pollinators of G. odoratissima.

\section{Data collection}

\section{Plant populations}

Plants were sampled during the middle of the flowering season, from 9th to 24th of July 2002 in two populations, "Münstertal", close to the village Tschierv, Graubünden $\mathrm{CH}$ (1,800 m above sea; 26 plants), and "Ofenpass", $2.2 \mathrm{~km} \mathrm{NW}$ of "Münstertal" on the top of the pass $(2,180 \mathrm{~m}$ above sea; 70 plants; see Huber et al. 2005 for map). In both populations, a randomly chosen sample of plants were marked, total number of flowers on the inflorescences counted, and fruit set counted after the flowering period.

\section{Floral scent collection}

Volatiles were sampled in the field from 96 plants as described in Huber et al. (2005) and Salzmann et al. (2007b). Uncut plants were inserted "in situ" into microwaveable oven bags $\left(\right.$ Nalophan $\left.{ }^{\circledR}\right)$. Air was pulled out of the bags by a battery operated vacuum pump equipped with an automatic counter of sample air volume. Volatiles were trapped onto $5 \mathrm{mg}$ of Porapak Q sealed in a glass vial. From each individual plant one sample was collected between 1000 and $1400 \mathrm{~h}$. Control samples were collected to discriminate compounds of plant origin from contaminants of the surrounding air. After a sampling period of $2 \mathrm{~h}$, volatiles were eluted from the Porapak using a hexane: acetone (9:1) mixture. Samples were sealed in glass vials and stored in a freezer at $-20^{\circ} \mathrm{C}$.

\section{Floral scent analysis}

For quantitative analysis, floral scent samples were analyzed using gas chromatography with flame ionization detection (GC-FID; Agilent 6890N). Before analysis, $100 \mathrm{ng}$ of octadecane was added to all samples as an internal standard. One $\mu$ of each odor sample was injected splitless at $40^{\circ} \mathrm{C}(1 \mathrm{~min})$ into the $\mathrm{GC}$ followed by opening the split valve and programming to $300^{\circ} \mathrm{C}$ at a rate of $10^{\circ} \mathrm{C} / \mathrm{min}$. The $\mathrm{GC}$ was equipped with a $\mathrm{HP} 5$ column (30 $\mathrm{m} \times 0.32 \mathrm{~mm}$ diameter and $0.25 \mu \mathrm{m}$ film thickness); helium was used as carrier gas at a flow of $2 \mathrm{ml} / \mathrm{min}$. For identification of compounds, samples were analysed by gas chromatography with mass selective detection (GC-MS). Of selected scent samples, $1.5 \mu \mathrm{l}$ were injected splitless into a GC (Carlo Erba Fractovap 4160) or GC-MS (Carlo Erba Mega 5160 coupled to a Finnigan MAT 212 instrument with INCOS computer system) at $40^{\circ} \mathrm{C}$ (3 min) followed by opening the split valve and programming to $230^{\circ} \mathrm{C}$ at a rate of $2.5^{\circ} \mathrm{C} / \mathrm{min}$. The analyses were made on a DBWAX column ( $\mathrm{J}$ and $\mathrm{W}$ Scientific; $30 \mathrm{~m} \cdot 0.32 \mathrm{~mm} \varnothing \cdot 0.25 \mathrm{~lm}$ film thickness). Compounds were identified by comparison of 
their mass spectra and retention times with those of authenticated reference samples. To match retention times of the compounds from the GC-FID and GC-MS analyses, some GCMS analyses were done on a HP5 column. (Z)-Isoeugenol and vanilline could not be separated with the chromatographic conditions used and were hence treated as one peak (subsequently called ( $Z$ )-isoeugenol). One compound with a mass spectrum similar to 1-phenyl-2,3-butandione could not be identified (MS: 162(45), 147(2), 119(40), 105(4), 91(100), 89(8), 65(14), 51(4), 43(37)) and is subsequently called the "unidentified compound". Absolute amounts of odor compounds were calculated using the internal standard method (Huber et al. 2005). Sampling times and sampling volumes were accounted for to calculate the absolute amount per inflorescence per liter sampled air (Table 1). These values were used for the selection analysis.

Phenotypic selection analysis

For the selection analysis, only the population with the larger sample size (Ofenpass) was used. Relative fruit production (number of fruits of individual plants divided by the mean number of fruits production in the population Ofenpass) was used as fitness estimate. Orchids are often limited in fruit set by pollination (Tremblay et al. 2005). In the current study populations of G. odoratissima, only around $40 \%$ of flowers per plant set fruit (Huber et al. 2005), suggesting fruit set being a good estimator of pollination success. Phenotypic correlations between number of flowers/plant and odor compounds were calculated by Pearson product-moment correlations. For assessing significant correlations, Bonferroni corrections were not considered.

\section{Data reduction}

Since it was impossible to include all scent compounds in the analyses ( $>40$ variables), we used only the most abundant compounds (amounts above $0.5 \mathrm{ng} /$ inflorescence $/ 1$; totaling 11 compounds, 7 active and 4 non-active). All independent variables were standardized to mean $=0$ and unit standard deviation. Because most compounds were significantly correlated (Table 2), we conducted a principal component analysis using all scent variables

Table 1 Comparison (mean \pm s.e.m.) of inflorescence size (total number of flowers), fruit set, and amount of scent compounds (in $\mathrm{ng} / \mathrm{l}$ ) in the two populations of Gymnadenia odoratissima

Active compounds are given in italics

$* P<0.05$; ** $P<0.01$, independent samples $t$-test

\begin{tabular}{lcc}
\hline Traits & Münstertal $(n=26)$ & Ofenpass $(n=70)$ \\
\hline Inflorescence size & $26.77 \pm 1.54$ & $26.77 \pm 1.15$ \\
Number of fruits & $11.19 \pm 1.43$ & $13.37 \pm 1.14$ \\
Phenylethyl acetate & $31.71 \pm 5.53$ & $24.32 \pm 3.82$ \\
Phenylacetaldehyde & $7.73 \pm 1.28$ & $15.58 \pm 3.12^{*}$ \\
Benzyl acetate & $34.04 \pm 7.57$ & $21.12 \pm 3.18$ \\
1-Phenyl-2,3-butandione & $4.98 \pm 1.18$ & $14.95 \pm 3.11^{* *}$ \\
Benzaldehyde & $8.59 \pm 1.38$ & $10.36 \pm 1.63$ \\
Eugenol & $8.95 \pm 1.99$ & $4.93 \pm 1.05$ \\
Unidentified & $2.14 \pm 0.46$ & $3.54 \pm 0.82$ \\
(Z)-Isoeugenol & $2.56 \pm 0.47$ & $1.18 \pm 0.27 *$ \\
Phenylethyl alcohol & $5.93 \pm 1.87$ & $5.44 \pm 1.35$ \\
$\alpha$-Pinene & $1.78 \pm 0.29$ & $2.13 \pm 0.40$ \\
Limonene & $0.63 \pm 0.13$ & $0.38 \pm 0.06$ \\
\hline
\end{tabular}




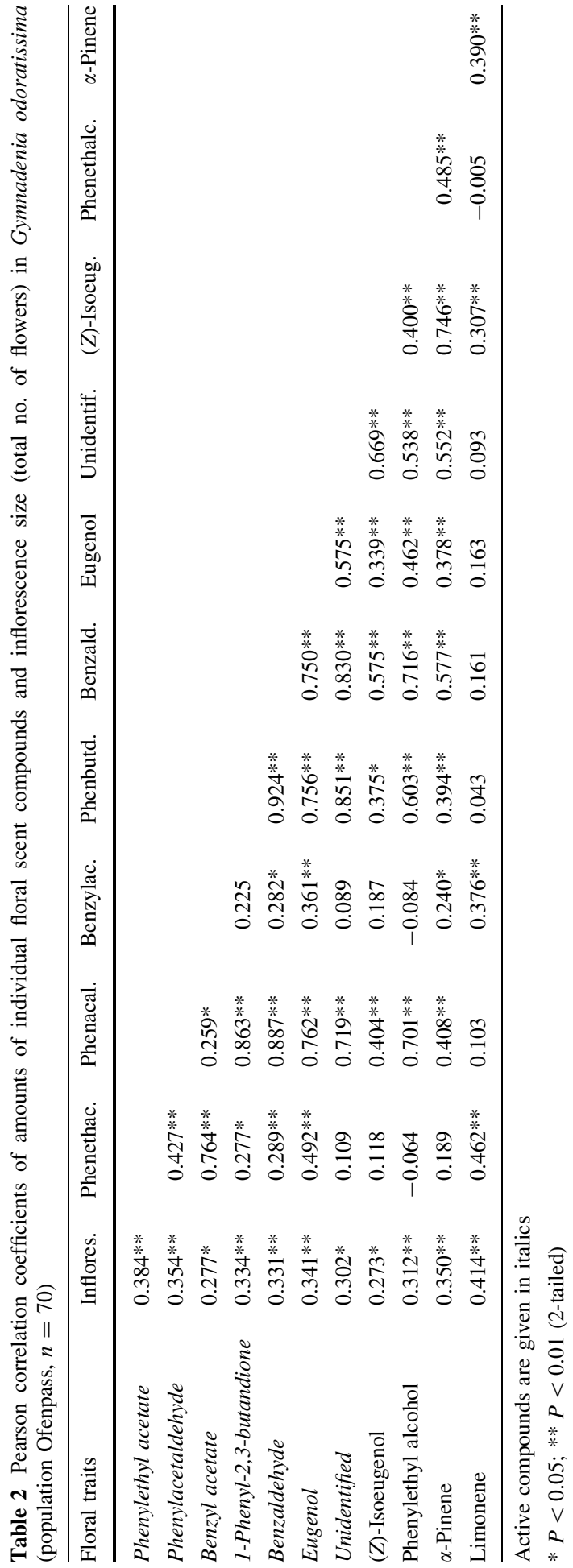


Table 3 Factor loadings of inflorescence size and scent compounds on principle components extracted (see "Materials and methods" sections for details of the principle components analysis)

Active compounds are given in italics; for each variable, the highest factor loading is given in bold

\begin{tabular}{lrrrr}
\hline Variables & PC1 & \multicolumn{1}{l}{ PC2 } & \multicolumn{1}{l}{ PC3 } & \multicolumn{1}{l}{ PC4 } \\
\hline Inflorescence size & 0.273 & 0.153 & 0.075 & $\mathbf{0 . 8 7 1}$ \\
Phenylethyl acetate & 0.204 & $\mathbf{0 . 8 9 5}$ & -0.020 & 0.237 \\
Phenylacetaldehyde & $\mathbf{0 . 9 1 4}$ & 0.191 & 0.121 & 0.130 \\
Benzyl acetate & 0.106 & $\mathbf{0 . 8 9 2}$ & 0.125 & 0.063 \\
1-Phenyl-2,3-butandione & $\mathbf{0 . 9 3 6}$ & 0.142 & 0.142 & 0.039 \\
Benzaldehyde & $\mathbf{0 . 8 9 0}$ & 0.136 & 0.361 & 0.073 \\
Eugenol & $\mathbf{0 . 7 8 3}$ & 0.379 & 0.080 & 0.092 \\
Unidentified & $\mathbf{0 . 7 3 6}$ & -0.030 & 0.493 & -0.005 \\
(Z)-Isoeugenol & 0.300 & 0.048 & $\mathbf{0 . 8 8 9}$ & 0.029 \\
Phenylethyl alcohol & $\mathbf{0 . 7 3 2}$ & -0.330 & 0.218 & 0.275 \\
$\alpha$-Pinene & 0.294 & 0.085 & $\mathbf{0 . 8 2 4}$ & 0.227 \\
Limonene & -0.152 & 0.442 & 0.424 & $\mathbf{0 . 5 8 0}$ \\
\hline
\end{tabular}

and total number of flowers (inflorescence size). Four principal components (PCs) with an eigenvector above 0.5 were extracted (Table 3 ). For a better interpretation of the principal components, we rotated them using the orthogonal rotation method varimax. Varimax simplifies the interpretation because after this rotation each original variable tends to be associated with one (or a small number) of factors, and each factor represents only a small number of variables. In addition, the factors can often be interpreted from the opposition of few variables with positive loadings to few variables with negative loadings (Hair et al. 2009). The four factors explained $84 \%$ of the total variance. These factors were used as independent variables in the selection analysis.

\section{Phenotypic selection}

Phenotypic selection on individual PCs was estimated by selection differentials and gradients, respectively. Linear selection differentials were estimated as the univariate regression coefficients using PCs as independent variable. The linear selection gradient, $\beta$, was computed from the standardized partial-regression coefficients of a linear multiple regression of relative fitness on all traits. (Lande and Arnold 1983). However, as we used only orthogonal independent variables (PC factors) in the selection analysis, selection differentials and gradient were identical.

We also used structural equation modeling (SEM) with latent constructs (Grace 2006) to estimate selection on the phenotypic traits studied through female fitness. SEM allows for the analysis of complex relationships between various variables and fitness. In addition, this method allows the consideration of multidimensional characters, like scent bouquets, by means of latent variables (Grace 2006). We created two latent variables, "active compounds" and "non-active compounds". The former variable was defined by the seven active compounds, whereas the latter was defined by the remaining 4 non-active compounds. We built an a priori over-identified saturated model, where plant relative fitness (number of fruits) was directly connected to the two latent variables and flower number. The total path coefficients generated by the SEMs can be interpreted as the total direct selection acting on each phenotypic trait. Afterwards, we built a set of alternative nested models by constraining to zero those paths having non-significant path coefficients. Model building was finished when all variables in the resulting model had significant path 
coefficients. All models were solved minimizing yield-parameter estimates through an iterative process that uses generalized least squares shifting to maximum likelihood as discrepancy functions. We used maximum-likelihood estimation (MLE) on the variancecovariance matrix to test the goodness of fit of the models. Structural equation modeling was performed with SEPATH procedure in Statistica 7.0. To select the best fitting model(s), we performed an information-theoretic approach (Burnham and Anderson 2002). We first selected those models obtaining an appropriate goodness of fit $(P>0.05$, Grace 2006). From this set of candidate models, we calculated: (1) the Akaike information criterion (AIC); (2) the second-order $\mathrm{AIC}\left(\mathrm{AIC}_{\mathrm{c}}\right)$ as

$$
\mathrm{AIC}_{\mathrm{c}}=\mathrm{AIC}+\frac{2 k(k+1)}{n-k-1}
$$

where $k$ is the number of parameters and $n$ the sample size; (3) the $\Delta \mathrm{AIC}_{\mathrm{c}}$ differences between models $\left(\mathrm{AIC}_{\mathrm{c}}\right)$; (4) the likelihood of each model, given data $($ gilx $)=\mathrm{e}^{-0.5 \Delta \mathrm{AICc}}$; and (5) the Akaike weights of each model $i$ of the $R$ candidate models as

$$
w_{i}=\frac{e^{-0.5 \Delta \mathrm{AICc}_{\mathrm{i}}}}{\sum_{r=1}^{R} e^{-0.5 \Delta \mathrm{AICc}_{\mathrm{i}}}}
$$

$w_{i}$ is taken as the weight of the evidence in favor of a given model $i$ from a set of $R$ candidate models, taking into account that $\sum_{i=1}^{r} w_{i}=1$. All models having $w_{i}>0.7$ were considered an appropriate representation of the raw data (Burnham and Anderson 2002).

\section{Results}

A comparison of the traits investigated in the two populations is given in Table 1. Total number of flowers, fruits set and the amounts of most floral scent compounds, with the exception of phenylacetaldehyde, 1-phenyl-2,3-butanione, and ( $Z$ )-isoeugenol were not significantly different among populations. In the subsequent analysis, however, only the population with the larger number of samples (Ofenpass) was used. Most compounds were positively correlated with inflorescence size and with each other (Table 2). Significant linear selection gradients, estimated by multivariate regression, were found for PC1 (positive), PC3 (negative), and PC4 (positive; Table 4). The saturated structural equation model (model 1 in Table 5) did not appropriately describe the data since it has a very low AIC weight value and some path coefficients were non-significant. The second model, built by eliminating the effect of non-active compounds on flower number, was also inappropriate, because of its low AIC weight (Table 5). Finally, the model built by eliminating the

Table 4 Multivariate selection coefficients in Gymnadenia odoratissima $(n=70)$. Significant

\begin{tabular}{|c|c|}
\hline Principle components & Linear selection gradient \\
\hline PC1 & $0.164 \pm 0.07 *$ \\
\hline PC2 & $-0.027 \pm 0.07$ \\
\hline PC3 & $-0.260 \pm 0.07 * * *$ \\
\hline PC4 & $0.344 \pm 0.07 * * *$ \\
\hline $\mathrm{R}^{2}$ & 0.416 \\
\hline $\mathrm{F}$ & $11.57 * * *$ \\
\hline
\end{tabular}
coefficients are given in bold 
Table 5 Summary of the model selection in the structural equation modelling (SEM)

\begin{tabular}{llrlrlll}
\hline Model & $\mathrm{k}$ & \multicolumn{1}{l}{ AIC } & \multicolumn{1}{l}{$\mathrm{AIC}_{\mathrm{c}}$} & \multicolumn{1}{c}{$\Delta \mathrm{AIC}_{\mathrm{c}}$} & $\xi(\mathrm{gil})$ & Akaike weights & Path constrained to zero \\
\hline 1 & 28 & 12.601 & 39.2240 & 10.3492 & 0.00565838 & 0.004656 & \\
2 & 27 & 7.612 & 31.9991 & 3.1244 & 0.20967612 & 0.172525 & Non Active $\rightarrow$ Flower number \\
3 & 26 & 6.589 & 28.8747 & 0.0000 & 1.00000000 & 0.822819 & Active $\rightarrow$ Flower number \\
\hline
\end{tabular}

$k$ number of parameters, $A I C$ Akaike information criterion, $A I C_{c}$ second-order $\mathrm{AIC}, \triangle A I C_{c} \mathrm{AIC}_{\mathrm{c}}$ differences, $\xi(g i \mid x)$ likelihood of each model

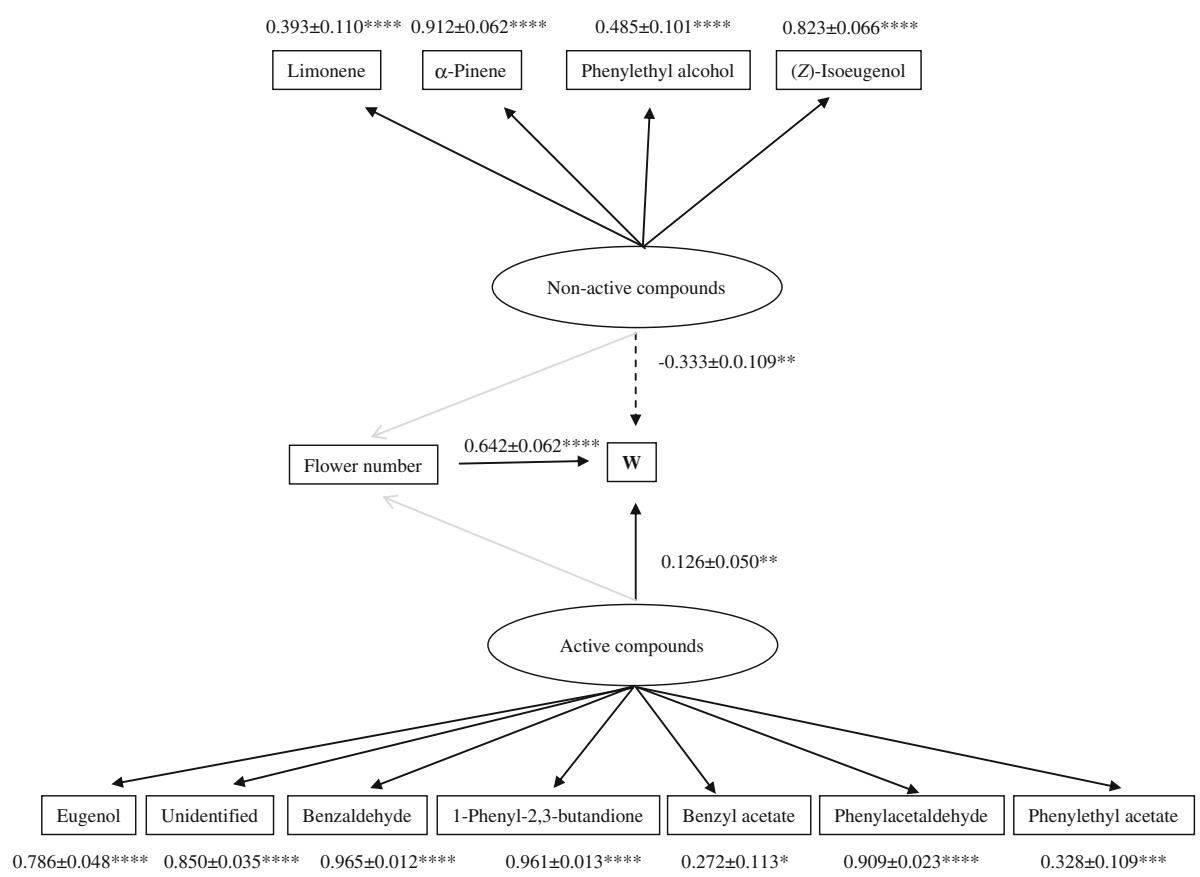

Fig. 1 Most parsimonious model (model 3 in Table 5) showing the causal relationships between active and non-active compounds, total number of flowers and fitness in Gymnadenia odoratissima $(* P<0.05$; ** $P<0.01$; *** $P<0.001$; **** $P<0.0001$,). Path coefficients in grey indicate the path from the saturated model (model 1 in Table 5) constrained to zero in model 3

effect of active compounds on flower number (model 3 in Table 5) was the most parsimonious, since it had a very high value of AIC weight (Table 5) and all the path coefficients were significant (Fig. 1). This model indicates that "active compounds", when put together as a compound variable, positively related to fitness, whereas "non-active compound" related to fitness in a negative way.

\section{Discussion}

Our study has demonstrated the occurrence of positive directional selection on G. odoratissima inflorescence size, as well as positive and negative directional selection on floral 
scent compounds. In our analysis, inflorescence size is mostly represented by PC 4 (Table 3) which showed a positive selection gradient, and our structural equation modeling approach also indicated a strong positive effect of inflorescence size on reproductive fitness. Flower and inflorescence size has been previously shown to be under positive directional selection (Benitez-Vieyra et al. 2006; Maad 2000; Maad and Alexandersson 2004; O'Connell and Johnston 1998), but much less is known about selection on floral scent. The importance of VOCs in the behavioral ecology of several insect groups, however, suggests that pollinator-mediated selection on floral fragrance is widespread in insect pollinated plants (Schiestl 2010). Floral scent is typically composed of many different compounds, comprising usually species-specific floral scent bouquets. Although both nonadaptive and adaptive processes likely contribute to the evolution of floral scent (Schiestl 2010), classic examples of pollinator-mediated selection on intra-specific scent-morphs suggest a prominent role of adaptation to the pollinators' sensory ecology. For example, Polemonium viscosum produces skunky smelling flowers primarily at low altitudes, which are preferentially visited by flies, whereas sweet smelling flowers occur at high altitudes and are primarily pollinated by bumble bees (Galen et al. 1987). Because flies are smaller than bumble bees, the flower preference of the respective pollinators create disruptive selection on flower size in this plant species (Galen 1989). A similar example is the Japanese herb Cimicifuga simplex with 3 morphs, one of them with distinct floral scent, attracting different pollinators at different altitudes (Pellmyr 1986). As yet, however, no study has examined direct phenotypic selection on scent compounds.

Selection on floral scent can be brought about by its function of attracting pollinators to inflorescences (Cunningham et al. 2004; Dötterl et al. 2006; Huber et al. 2005; Plepys et al. 2002). Floral VOCs, however, may also negatively connect to fitness by deterring pollinators (Ômura et al. 2000) or attracting herbivores (Baldwin et al. 1997; Theis 2006). Initial attraction of pollinators is expected to be mirrored by positive directional selection on such attractive compounds, because higher amounts of scent usually lead to higher attractiveness of the emitter or better detectability from greater distances (Schiestl 2004; Waelti et al. 2009). Our structural equation modeling shows that in G. odoratissima, "active" compounds connect positively to fitness, whereas non-active connected negatively to fitness. This finding was confirmed by the positive selection gradient for PC1 and the negative selection gradient for PC3. In our analysis, PC1 represents the major "active" aromatics produced by $G$. odoratissima, phenylacetaldehyde, 1-phenyl-2,3-butandione, benzaldehyde, eugenol, and the active unidentified compound (Table 3 ). The pollinatorattracting function of phenylacetaldehyde has been shown previously, as this compound attracts G. odoratissima pollinators to traps in the field (Huber et al. 2005). Therefore, positive directional selection on these compounds may mirror the higher attractiveness for pollinators of plants emitting higher amounts of these compounds. On the other hand, negative directional selection on floral scent compounds suggests reproductive fitness trade-offs involved in the production of certain volatiles. PC 3 represents mostly the nonactive aromatic $(Z)$-isoeugenol and the monoterpene $\alpha$-pinene (Table 3 ). We suggest three mutually non-exclusive possibilities explaining the negative effect of these compounds on fruiting success mediated by pollination. (1) The compounds may interact with active compounds in the blend and decrease their attractiveness. It is well documented that the addition of $\alpha$-pinene strongly decreases receptor responses and behavioral attractiveness of certain compounds in euglossine bees (Schiestl and Roubik 2003; Williams and Dodson 1972). Despite no deterrence effects of pure $\alpha$-pinene was found on naïve or experienced moths (Cunningham et al. 2004), its effects on the attractiveness of other compounds in a blend has not yet been tested in moths. (2) On the other hand, floral volatiles may also 
directly deter insects from flowers and thus function in plant defense (Ibrahim et al. 2001; O'Reilly-Wapstra et al. 2007). Such deterrence, primarily targeted at herbivores, may also impact on pollinator attractiveness hence representing a trade-off between attraction (of mutualists) and deterrence (of antagonists; Theis et al. 2009). Although damage to flowers and fruits has not been observed in our alpine study population, Gymnadenia inflorescences are sometimes attacked by aphids or snails which may cause considerable damage (Schiestl unpublished). The net fitness effect of deterrence compounds may thus depend on the herbivore pressure in populations. In populations with low herbivore pressure, repelling compounds may cause a net negative fitness effect for the plants, leading to selection for reduced amounts of these volatiles. (3) Lastly, volatiles may also directly attract florivores and thus be negatively connected to reproductive fitness (Baldwin et al. 1997; Theis 2006).

Our results offer new insights into the evolution of scent bouquets through directional selection, assuming that floral scent has a heritable component. We anticipate that future experiments will be able to unravel the details of this process. Behavioral experiments with model pollinators could address the question which compounds attract/deter pollinators and herbivores and how the attractiveness of individual compounds changes in a blend. Although several studies have investigated deterrence effect of volatile compounds on herbivores (e.g. Ibrahim et al. 2001; O'Reilly-Wapstra et al. 2007), little is known about deterrence effects of volatiles on pollinators (but see Ômura et al. 2000). Meta analyses of the available data, however, suggest that monoterpenes may be primarily deterring, whereas aromatic compounds have initial attraction function (Junker and Blüthgen 2010; Schiestl 2010). On the plant side, experimental manipulation of odor bouquets by adding or removing specific compounds may help to understand the impacts of given compound emission on the fitness of a plant. The recent advent of silencing specific odor genes in genetically transformed plants offers exciting opportunities in this respect (Kessler et al. 2008).

Acknowledgments We would like to thanks three anonymous reviewer as well as the handling editor, Arien Biere, for their valuable comments on an earlier version of this manuscript. We also thank Roman Kaiser for his help with identifying scent compounds.

\section{References}

Aragon S, Ackerman JD (2004) Does flower color variation matter in deception pollinated Psychilis monensis (Orchidaceae)? Oecologia 138:405-413

Ayasse M, Schiestl FP, Paulus HF, Löfstedt C, Hansson BS, Ibarra F, Francke W (2000) Evolution of reproductive strategies in the sexually deceptive orchid Ophrys sphegodes: how does flower-specific variation of odor signals influence reproductive success? Evolution 54:1995-2006

Baldwin IT, Preston C, Euler M, Gorham D (1997) Patterns and consequences of benzyl acetone floral emissions from Nicotiana attenuata plants. J Chem Ecol 23:2327-2343

Benitez-Vieyra S, Medina AM, Glinos E, Cocucci AA (2006) Pollinator-mediated selection on floral traits and size of floral display in Cyclopogon elatus, a sweat bee-pollinated orchid. Funct Ecol 20:948-957

Burnham KP, Anderson DR (2002) Model selection and multimodel inference: a practical-theoretic approach. Springer, Heidelberg

Chess SKR, Raguso RA, LeBuhn G (2008) Geographic divergence in floral morphology and scent in Linanthus dichotomus (Polemoniaceae). Am J Bot 95:1652-1659

Chittka L, Thomson JD, Waser NM (1999) Flower constancy, insect psychology, and plant evolution. Naturwissenschaften 86:361-377

Cunningham JP, Moore CJ, Zalucki MP, West SA (2004) Learning, odour preference and flower foraging in moths. J Exp Biol 207:87-94

Dötterl S, Jurgens A, Seifert K, Laube T, Weissbecker B, Schutz S (2006) Nursery pollination by a moth in Silene latifolia: the role of odours in eliciting antennal and behavioural responses. New Phytol 169:707-718 
Galen C (1989) Measuring pollinator-mediated selection on morphometric floral traits. Bumblebees and the alpine sky pilot, Polemonium viscosum. Evolution 43:882-890

Galen C, Zimmer KA, Newport ME (1987) Pollination in floral scent morphs of Polemonium viscosum-a mechanism for disruptive selection on flower size. Evolution 41:599-606

Gomez JM (2000) Phenotypic selection and response to selection in Lobularia maritima: importance of direct and correlational components of natural selection. J Evol Biol 13:689-699

Gomez JM, Bosch J, Perfectti F, Fernandez JD, Abdelaziz M, Camacho JPM (2008) Spatial variation in selection on corolla shape in a generalist plant is promoted by the preference patterns of its local pollinators. Proc R Soc Lond B Biol Sci 275:2241-2249

Goyret J, Pfaff M, Raguso RA, Kelber A (2008) Why do Manduca sexta feed from white flowers? Innate and learnt colour preferences in a hawkmoth. Naturwissenschaften 95:569-576

Grace JB (2006) Structural equation modeling and natural systems. Cambridge University Press, Cambridge

Hair JF, Black WC, Babin BJ, Anderson RE (2009) Multivariate data analysis, 7th edn. Prentice Hall, Englewood Cliffs

Herrera CM, Castellanos MC, Medrano M (2006) Geographical context of floral evolution: towards an improved research programme in floral diversification. In: Harder LD, Barrett SCH (eds) Ecology and Evolution of flowers. Oxford University Press, Oxford, pp 278-294

Huber FK, Kaiser R, Sauter W, Schiestl FP (2005) Floral scent emission and pollinator attraction in two species of Gymnadenia (Orchidaceae). Oecologia 142:564-575

Ibrahim MA, Kainulainen P, Aflatuni A, Tiilikkala K, Holopainen JK (2001) Insecticidal, repellent, antimicrobial activity and phytotoxicity of essential oils: with special reference to limonene and its suitability for control of insect pests. Agric Food Sci Finl 10:243-259

Johnson SD (2006) Pollinator driven speciation in plants. In: Harder LD, Barrett SCH (eds) Ecology and evolution of flowers. Oxford University Press, Oxford, pp 295-310

Junker RJ, Blüthgen N (2010) Floral scents repel facultative flower visitors, but attract obligate ones. Ann Bot (in press)

Kessler D, Gase K, Baldwin IT (2008) Field experiments with transformed plants reveal the sense of floral scents. Science 321:1200-1202

Knudsen JT, Eriksson R, Gershenzon J, Stahl B (2006) Diversity and distribution of floral scent. Bot Rev $72: 1-120$

Lande R, Arnold SJ (1983) The measurement of selection on correlated characters. Evolution 37:1210-1226

Maad J (2000) Phenotypic selection in hawkmoth-pollinated Platanthera bifolia: targets and fitness surfaces. Evolution 54:112-123

Maad J, Alexandersson R (2004) Variable selection in Platanthera bifolia (Orchidaceae): phenotypic selection differed between sex functions in a drought year. J Evol Biol 17:642-650

Mant J, Peakall R, Schiestl FP (2005) Does selection on floral odor promote differentiation among populations and species of the sexually deceptive orchid genus Ophrys? Evolution 59:1449-1463

Melendez-Ackerman E, Campbell DR (1998) Adaptive significance of flower color and inter-trait correlations in an Ipomopsis hybrid zone. Evolution 52:1293-1303

Melendez-Ackerman E, Campbell DR, Waser NM (1997) Hummingbird behavior and mechanisms of selection on flower color in Ipomopsis. Ecology 78:2532-2541

O'Connell ML, Johnston MO (1998) Male and female pollination success in a deceptive orchid, a selection study. Ecology 79:1246-1260

O'Reilly-Wapstra JM, Iason GR, Thoss V (2007) The role of genetic and chemical variation of Pinus sylvestris seedlings in influencing slug herbivory. Oecologia 152:82-91

Ômura H, Honda K, Hayashi N (2000) Floral scent of Osmanthus fragrans discourages foraging behavior of cabbage butterfly, pieris rapae. J Chem Ecol 26:655-666

Pellmyr O (1986) Three pollination morphs in Cimicifuga simplex; incipient speciation due to inferiority competition. Oecologia 68:304-307

Plepys D, Ibarra F, Lofstedt C (2002) Volatiles from flowers of Platanthera bifolia (Orchidaceae) attractive to the silver y moth, Autographa gamma (Lepidoptera : Noctuidae). Oikos 99:69-74

Raguso RA (2008) Wake up and smell the roses: the ecology and evolution of floral scent. Annu Rev Ecol Evol Syst 39:549-569

Salzmann CC, Cozzolino S, Schiestl FP (2007a) Floral scent in food-deceptive orchids: Species specificity and sources of variability. Plant Biol 9:720-729

Salzmann CC, Nardella AM, Cozzolino S, Schiestl FP (2007b) Variability in floral scent in rewarding and deceptive orchids: the signature of pollinator-imposed selection? Ann Bot 100:757-765

Schiestl FP (2004) Floral evolution and pollinator mate choice in a sexually deceptive orchid. J Evol Biol 17:67-75

Schiestl FP (2010) The evolution of floral scent and insect chemical communication. Ecol Lett 13:643-656 
Schiestl FP, Roubik DW (2003) Odor compound detection in male euglossine bees. J Chem Ecol 29:253-257

Schiestl FP, Schlüter PM (2009) Floral isolation, specialized pollination, and pollinator behavior in orchids. Annu Rev Entomol 54:425-446

Schiestl FP et al (2003) The chemistry of sexual deception in an orchid-wasp pollination system. Science 302:437-438

Steinebrunner F, Schiestl FP, Leuchtmann A (2008) Ecological role of volatiles produced by epichloe: differences in antifungal toxicity. FEMS Microbiol Ecol 64:307-316

Streisfeld MA, Kohn JR (2007) Environment and pollinator-mediated selection on parapatric floral races of Mimulus aurantiacus. J Evol Biol 20:122-132

Theis N (2006) Fragrance of canada thistle (Cirsium arvense) attracts both floral herbivores and pollinators. J Chem Ecol 32:917-927

Theis N, Kesler K, Adler LS (2009) Leaf herbivory increases floral fragrance in male but not female Curcubita pepo subsp. texana (Cucurbitaceae) flowers. Am J Bot 96:897-903

Tremblay RL, Ackerman JD, Zimmerman JK, Calvo RN (2005) Variation in sexual reproduction in orchids and its evolutionary consequences: a spasmodic journey to diversification. Biol J Linn Soc 84:1-54

Vereecken NJ, Schiestl FP (2008) The evolution of imperfect floral mimicry. Proc Natl Acad Sci USA 105:7484-7488

Waelti MO, Mühlemann JK, Widmer A, Schiestl FP (2008) Floral odour and reproductive isolation in two species of Silene. J Evol Biol 21:111-121

Waelti MO, Page PA, Widmer A, Schiestl FP (2009) How to be an attractive male: floral dimorphism and attractiveness to pollinators in a dioecious plant. BMC Evol Biol 9

Wiemer AP, More M, Benitez-Vieyra S, Cocucci AA, Raguso RA, Sersic AN (2009) A simple floral fragrance and unusual osmophore structure in Cyclopogon elatus (Orchidaceae). Plant Biol 11:506-514

Williams NH, Dodson CH (1972) Selective attraction of male euglossine bees to orchid floral fragrances and its importance in long distance pollen flow. Evolution 26:84-95 